\title{
DEBATE
}

"Debate" is a series offering opposing sides of a continuing, controversial issue in tobacco control. In this and the three following articles, the likely future of the tobacco industry is discussed and debated by Clive Bates of ASH in London, Rob Cunningham from the Canadian Cancer Society, Stan Glantz from the Institute of Health Policy Studies at the University of California, San Francisco, and Michelle Scollo, from the VicHealth Tobacco Control Centre in Victoria, Australia

\section{What is the future for the tobacco industry?}

Here is a best case health scenario for the future of the tobacco industry. Despite the hopes of some of the health lobby, the industry will survive even the most severe litigation assaults. Even the worst judgements would leave the tobacco industry intact. Diversification into completely new businesses will not prove to be a commercial reality for the main companies involved because there is no advantage to non-tobacco business to be merged with tobacco. Regulators will assert proper jurisdiction over tobacco and force the companies to make products that are less harmful by setting emissions limits and product standards - for example, to reduce or remove carbon monoxide, carcinogenic nitrosamines, or many other toxins in tobacco smoke. Over time the delivery of nicotine through tobacco will evolve from combustion, through heating and oral use, and eventually to extracts and purified distillates.

Nicotine-the psychoactive chemical that differentiates smoking tobacco from smoking cabbage-will become recognised as the real "product". The tobacco companies will face competition from new forms of nicotine delivery unconnected with tobacco and will have to respond by using the power of their brands to move into this market. Nicotine will continue to be widely used in society and many will be addicted, but the risk to users will be reduced - at least the option to reduce risk will be available. Concern about "addiction" rather than "disease" will become the defining reason not to use nicotine. Concern about "addiction followed by disease" will become the dominant reason not to smoke tobacco.

\section{Super-litigation can wound but it will not kill}

For some health activists the only future for the tobacco industry is no future. It is hard to see how this will come about even in a gigantic Armageddon of US super-litigation. Imagine a vast and successful "zillion" dollar law suit. All appeals have failed. It is the worst case scenario for them and the tobacco industry has nowhere to go. But what actually happens? The first option for the companies is to try to pass the costs to smokers by raising the price. A surprisingly large amount of money can be raised through this route. The $\$ 206$ billion multi-state settlement with the US states has been brushed off with a modest 40 cents price rise. If the US companies raised prices to the levels they have already reached in the UK (currently US $\$ 6.40$ for Marlboro), then over 20 years, they could fund over one trillion dollars. So a knockout blow would need to be very large indeed.

But suppose the courts did deliver that knockout or the companies could not raise prices because foreign tobacco companies not involved in the litigation entered the market. This means the companies have to find the money from shareholders rather than customers. Even if litigation could take down Philip Morris, it would be shareholders that lost everything. But the most valuable entity owned by the shareholders is the Philip Morris (PM) business and its global brand Marlboro-with a market value of US\$82 billion. They would have to sell the tobacco business as a going concern-complete with the existing factories, distribution channels, management, and brands. The pension funds, mutuals, and individuals that currently own PM shares would take the hit. The company would go on, though with different owners.

Litigation will continue to have many benefits and rich rewards, not least as a rolling "truth machine" and a reason for the companies to overhaul their business practices. However, it cannot stop the sale of a product that people want or need to buy, nor can it eliminate the inherent value in a big business run as a going concern able to meet the demand.

Why complete diversification is unlikely The problem with the diversification idea is that the benefits flow one way. Pure tobacco stocks are volatile and prone to regulatory or litigation risks. For a tobacco business, a merger with a food or financial services operation helps to dampen the fluctuations in the overall stock price. The problem is that it is hard to see any advantages to a viable food or financial services business in being merged with tobacco. Not only is there the volatility of the tobacco part of the business and the risk that all the assets will be seized to pay for tobacco litigation claims, but also boycotts, management distraction, shareholder actions and so on.

Diversification only really works where there is a synergistic advantage in which the parts of the conglomerate benefit from being part of 
the whole. Some of the tobacco brands could be valuable to other businesses, but the problem for the tobacco companies is that the governments are clamping down on tobacco advertising and rightly suspect that so-called brand diversification is mainly an attempt to circumvent tobacco advertising restrictions.

How can the tobacco market evolve?

Before describing a possible future for tobacco, it is necessary to name some unlikely culprits behind the epidemic of tobacco related disease. I believe the pharmaceutical regulators are responsible for thousands and maybe millions of unnecessary tobacco related deaths. It is a shocking truth, but perverse regulation of the market for nicotine has granted an unregulated monopoly to the worst, most deadly suppliers - the tobacco industry. This is not a mere complaint about the regulatory hurdles faced by makers of smoking cessation products - which are often formidable-it is much more serious than that. It is about who can offer nicotine as a lifestyle drug.

Imagine a hypothetical new product-let us call it "Satisfaction". Assume it has the nicotine delivery of a Marlboro cigarette-not only the same dose of nicotine but the same speed of action and "impact". To make it palatable it has been flavoured, perhaps with something fashionable like tequila. As an ironic marketing gambit, a hard living cadaverous rock star has been enlisted to endorse the product. It is packaged like "poppers" (capsules of amyl nitrate) and sold initially in bars and clubs to give it an "underground" feel. Of course, "Satisfaction" is powerfully addictive and the nicotine has effects on the heart and other health consequences. It appeals to the young and there is concern that teenagers might start to use it. In many respects, it is similar to a Marlboro cigarette, except that it does not expose the user (or people nearby) to inhalation of 4000 products of tobacco combustion and greatly reduces the risk of disease associated with long term nicotine use. Even if it is not entirely safe, "Satisfaction" is far less harmful than smoking tobacco.

What would you think about this product? Would you fight to ban it, or fight to have it introduced? I would want it introduced. It is an alternative that introduces no new risks that are not already present with cigarettes, but greatly reduces smoking related health risk. The truth is, however, that we are unlikely to be asked. No pharmaceutical regulator would approve "Satisfaction", and knowing the impossibility of bringing such a product to market, no food or drug company would even begin any sort of development.

Underpinning this view is a clear distinction between the use of the drug nicotine and the harm caused by its manner of delivery. This is a crucial distinction - health promotion efforts have implicitly tried to tackle the harm and the underlying drug use simultaneously. This approach has had some success with some groups in some societies. The problem is the remaining people who continue to take nicotine by smoking tobacco. For them, it is possible to tackle the harm caused by the manner of delivery independently of the drug syndrome. This is not to say that nicotine dependence should not be tackled, but "drug problems" are social phenomena and should be tackled by addressing the underlying socioeconomic and cultural causes, backed up with treatment for dependence.

\section{Where next?}

The impetus for change will come from steady regulatory pressure on the harm caused by nicotine delivery through tobacco smoke. We already know there are many patents and techniques for reducing toxins in tobacco smokefor example, to remove nitrosamines, carbon monoxide, phenols, hydrogen cyanide, and many more. This would be the start of a long process of "purifying" nicotine delivery. Smokers take the nicotine they need from smoke, but they inhale the toxins that come with the nicotine. By reducing the concentration of toxins in the smoke relative to nicotine the smoke will become genuinely less hazardous-unlike so-called low tar cigarettes. Continuous regulatory pressure would force innovation in tobacco product design that would suggest an evolution from burning to heating tobacco, and then perhaps into products which are sucked or chewed, or the active ingredients extracted and repackaged.

In parallel, it is necessary to open the nicotine market to competitors of Big Tobacco. That means changing the approach of some very entrenched conservative pharmaceutical regulators who have never had to face their de facto complicity in protecting and nurturing tobacco interests. One of the toughest questions with new nicotine products is the extent to which established tobacco control policies, such as taxation, advertising restrictions, and health promotion campaigns should be applied. These products are highly desirable alternatives to smoking tobacco, but they are not safe and are addictive. To compete with tobacco they would have to be marketed, as lifestyle products rather than medicines. At the moment, the regulatory approach is "reckless extreme caution" in the shape of a total ban on competitive nicotine products that offers the entire market to tobacco.

Director, Action on Smoking and Health

CLIVE BATES

London, UK

clive.bates@dial.pipex.com

The author would like to acknowledge the contribution to this article of David Sweanor through many conversations and challenging ideas. The views and heresies herein are entirely my own. 